\title{
Biomedical Engineering Education, Virtual Campuses and the Bologna Process
}

\author{
E.G. Salerud ${ }^{1}$ and Michail Ilias ${ }^{1}$ \\ Department of Biomedical Engineering, Linköping university, Linköping, Sweden
}

\begin{abstract}
Higher education in Europe can be divided into before and after the Bologna Declaration, the most revolutionary process in modern education. Biomedical engineering, an emerging "subject" during the last 40 years, strongly interdisciplinary, fragmented and lacking of international coordination, may benefit from this harmonization process. An early initiative such as BIOMEDEA has made a contribution through proposing biomedical engineering foundations for building a common curriculum among higher education institutions. A common curriculum would presumably contribute to student and teacher mobility, certification and accreditation and as a consequence promote increased international employability. The virtual campus action extends or adds values to already existing educational exchange networks such as Erasmus, important in student mobility and educational harmonization and recognition. A virtual education dimension is added to European co-operation, encouraged through the development of new organisational models for European institutions, promoting virtual mobility and recognition. Virtual campuses may have a possibility to bridge the gaps in national BME curricula all with respect to the action towards a consensus on European guidelines for the harmonization. The evaluation of the e-curricula is conformant with the roadmap of $\mathrm{BME}$ courses as defined by BIOMEDEA. Most courses are classified as second cycle courses on a Master level, supporting that studies in BME could be a continuation from cycle one. Learning environment and the students learning outcome, points towards a strong teacher-centred approach to learning. The transparency at all levels are low, a factor that might influence recruiting potential students to a programme, especially those students with working experience and an international background. To fulfil the Bologna Declaration and other steering documents for the higher education in an expanding European future there are still tasks to be solved regarding recognition, legalisation, pedagogical issues and employability looking for a harmonized solution.
\end{abstract}

Keywords - Biomedical engineering, Bologna, harmonization, virtual campus

\section{INTRODUCTION}

In 1999, the most paramount reform in higher education in Europe, took off with the Bologna Declaration. It was signed by 29 European countries in an action programme with a clear defined goal: "to create a European space for higher education in order to enhance the employability and mobility of citizens and to increase the international com- petitiveness of European higher education". To reach the goal a number of objectives [1] were specified:

- the adoption of a common framework of readable and comparable degrees

- the introduction of undergraduate and postgraduate levels in all countries, with first degrees no shorter than 3 years and relevant to the labour market

- ECTS-compatible credit systems also covering lifelong learning activities

- a European dimension in quality assurance, with comparable criteria and methods

- the elimination of remaining obstacles to the free mobility of students and teachers

Further a European Higher Education Area (EHEA) should be established by 2010 , now involving more signatories, focusing on curricular reforms and quality assurance. The aim of the European Higher Education Area is to provide citizens with choices from a wide and transparent range of high quality courses and benefit from smooth recognition procedures.

Biomedical Engineering (BME) constitutes a field where the need for harmonisation and comparability is readily seen. Although BME has been established within Europe for more than 40 years, it still has not managed to get recognition between European countries or internationally to this day. Shortcomings of funding opportunities, fragmentation of educational and research programmes, and a lack of international coordination between programmes are some of the unfortunate features characterising the field.

\section{BiomediCAL ENGINEERING EDUCATION}

\section{A. Biomedical engineering as a subject}

Undergraduate degrees in BME have been granted for many years. As an emerging field, biomedical engineering has been an interdisciplinary field; in which specialization occur after completing an undergraduate degree in a more traditional discipline of engineering or science. Biomedical engineers are supposed to be equally knowledgeable in engineering and the biological sciences. Comparing already established programmes, no defined common core or all required fundamental courses or a proposed curriculum, 
although in many programmes traditional courses in biomechanics and systems physiology are quite common.

A complete recognition and becoming a "subject" of its own is indispensable in BME and do not exist today but have to be defined in the near future $[2,3]$. However, the lack of agreements at the course levels does not mean that there is no similarity at the content level. In countries such as US recognition or accreditation is solved by a thorough evaluation of the Accreditation Board for Engineering and Technology, Inc. (ABET), a very demanding procedure, necessary for a BME programme to exist and be esteemed. Following the Bologna process aims at creating convergence and, thus, is not a path towards the "standardisation" or "uniformisation" but instead "harmonization" of European higher education. The fundamental principles of autonomy and diversity are respected, preserved and recognized.

The field of BME is progressing rapidly into new areas, quite often fusioning different technologies and methods from many different domains. The BME domain demands the students to develop multidisciplinary skills and knowledge and a possibility for life-long learning. Therefore, embracing pedagogical renewal as a part of new or revised curriculum in biomedical engineering education has been demanded. Harmonization with the Dublin descriptors on programme level is therefore inevitable. [4]

\section{B. BIOMEDEA - defining the curriculum}

BME, this emerging and evolving field, was early recognized and dedicated special attention to become harmonized with the Bologna Declaration because of its diversity and lack of common curriculum. More than 200 higher education institutions in Europe already offer educational programmes in Biomedical Engineering at all academic levels, but without any international coordination of contents and required qualifications. A harmonization and accreditation project "BIOMEDEA" [5] was initiated by Joachim Nagel and strongly supported by the IFMBE society in 2001. The aim of the project was to establishing Europe-wide consensus on guidelines:

- for the harmonization of high quality BME programmes, their accreditation and recognition.

- for the certification or even registration and continuing education of professionals working in the health care systems

Recognition among higher education institutions is an important factor in ensuring student and teacher mobility and accreditation has mostly impact on the transnational employability. To improve human health and quality of life it is of vital interest that the employer is confident that the employee has the necessary education, skill, training and responsible experience, and is capable of managing the technology served.

The BIOMEDEA project published in 2005 guidelines in recommending programme modules spanning the BME curriculum. Modules were attributed to:

- BME foundations

- BME in-depth topics

- Mathematics

- Natural Sciences

- Engineering

- Medical and Biological foundations

- General and social competencies

With the recommendations of BIOMEDEA, IFMBE, their national member societies, higher education institutions and stakeholders are able to comply with international harmonization of higher education, to show transparency and recognition and support mobility for education, training and employment.

\section{Virtual campuses - EVICAB}

Virtual campuses: Mobility of students and teachers do not always imply physical transfer. Using Information and communication technologies (ICT), may contribute to the quality of education and training and to Europe's progress towards a knowledge-based society. It may also have an impact on the harmonization of curricula and joint degrees. The eLearning Initiative and Action Plan, proposed by EU, encourage co-operation, networking and exchange of good practice at a European level. It also has the potential to realize the vision of technology serving lifelong learning. One action is the European virtual campuses and particularly the European Virtual Campus for Biomedical Engineering (EVICAB).

A virtual education dimension is added to European cooperation, encouraged through the development of new organisational models for higher European institutions, the virtual campuses, creating virtual mobility and recognition. It will add values to already existing exchange programmes like Erasmus, Comenius, etc. The objective of EVICAB is to develop, build up and evaluate sustainable, dynamic solutions for virtual mobility and e-learning that, according to the Bologna process, [6]

- mutually support the harmonization of the European higher education programmes

- improve the quality of and comparability between the programmes

- advance the post-graduate studies, qualification and certification 
Virtual European curriculum in BME cannot be obtained without first evaluating the existing curricula to be compared with a new or existing e-curriculum with good possibilities to strengthen harmonization, recognition and quality assurance. The survey is based on the BIOMEDEA curriculum proposal, extending the latter into the virtual domain.

The status report produced within the BIOMEDEA framework [7] showed that BME programmes are often offered in single institutes and therefore the programmes cannot cover all subfields of BME needed in education of highly specialized engineers and physicists. Therefore, Virtual campuses may have a possibility to bridge the gaps in national BME curricula all with respect to the action towards a consensus on European guidelines for the harmonization.

Evaluation: The evaluation was conducted through a manageable survey involving as many higher education institutions as possible, found in Biomedical Engineering Education in Europe - Status Reports (ref BIOMEDEA) and a wider search on the World Wide Web (WWW).

Basic course information was collected regarding number of existing courses and courses planned to run within the next couple of years. The major part of the survey was designed elucidating the degree of course compatibility to the Bologna declaration. The following general trends could be discerned:

- the course operative language is often the native language of the responsible university.

- the course most often belongs to the $2^{\text {nd }}$ cycle of qualification.

- the ECTS credit system is widely adopted.

The BIOMEDEA definitions seem to apply to the contents of the surveyed courses to a certain degree. The results showed that

- the majority of the foundations and modules of BME as defined by BIOMEDEA are covered by the pooled courses.

- still there is a need for defining other topics and descriptions not covered by BIOMEDEA.

The survey also included the most valuable resources for the support of student learning outcomes as judged by those offering the course. The following resources were pointed out in order of priority:

- in most courses the tutors were stated to be the most important.

- students' work, laboratory and demonstrations was highly valued.
A majority of courses was, according to those who responded, subject of measures assuring course quality in practice. The most common measures are:

- feedback by students.

- internal quality controls at a university level.

- peer review and internal work at an institutional level.

- controls by external bodies.

- use of field expertise in an educational context, assuring the quality of teaching or tutoring.

Transparency issues were also addressed revealing that:

- course outcomes are most often publicly available. The most frequent means of publication is the WWW.

- outcomes are as a rule directly delivered to the students, most often by means of handouts.

Finally, the survey tried to shed light on distance course benefits regarding life long learning and student mobility between countries. The results showed that:

- few BME professionals take advantage of distance education in order to support their continuing education.

- there is a limited number of foreign students attending distance courses.

\section{Conclusions}

In the EUA document "Trends IV: European Universities Implementing Bologna" [8] evidence is found that the two cycle implementation has been achieved at nation level in most countries. Positive reports are also available regarding the curricular reform focusing on the learning outcomes.

The evaluation of the e-curricula is conformant with the report since existing and planned courses seem to cover the proposed roadmap of BME courses as defined by BIOMEDEA. Most of the courses are classified as second cycle courses on a Master level, supporting the existence of a first cycle, and that studies in BME could be a continuation from cycle one.

Approaching pedagogical viewpoints and the students learning outcome, both on a programme and course level, the teacher-centred approach to learning is still dominating. However, students' work, labs and demonstrations could in this context, supporting a more student-centred approach.

All educational centres reported working with quality assurance issues on a local, department level. The routines for external quality assurance aren't clear and some showed willingness to comply with the European Network for Quality Assurance in Higher Education (ENQA) directives but without a declared roadmap and lack of transparency. 
The transparency at all levels are low, a factor that might influence recruiting potential students to a programme, especially those students with working experience and an international background.

Virtual campuses are an added value to existing exchange networks for mobility of students and teachers. To fulfil the Bologna Declaration and other steering documents for the higher education in an expanding European future there are still tasks to be solved regarding recognition, legalisation, pedagogical issues and employability looking for a harmonized solutions.

\section{ACKNOWLEDGMENT}

The project is funded by the European Commission under the program Education and Training

\section{REFERENCES}

1. THE BOLOGNA PROCESS at http://ec.europa.eu/education/policies/ educ/bologna/bologna en.html

2. Linsenmeier R.A. (2003) What makes a biomedical engineer? IEEE Eng. Med. Biol. Mag. Jul-Aug;22(4):32-38.

3. MBES position paper at http://www.eambes.org/docs/MBESposition-paper-final.pdf

4. Dublin descriptors at http://www.jointquality.nl/

5. Criteria for the Accreditation of Biomedical Engineering Programmes in Europe at http://www.biomedea.org/documents.htm

6. EVICAB at http://www.evicab.eu/

7. Biomedical Engineering Education in Europe - Status Reports at http://www.biomedea.org/ documents.htm

8. Trends IV: European Universities Implementing Bologna http://www.eua.be/fileadmin/user_upload/files/EUA1_documents/ TrendsIV_FINAL.1117012084971.pdf

Author: E. Göran Salerud

Institute: Department Biomedical Engineering

Street: Linköping university

City: Linköping

Country: Sweden

Email: gosal@imt.liu.se 